\title{
Explanation of mental processes involving consciousness through the consciousness model incorporating quantum mechanical activities of Though-carrying particle (TCP) and Thought retaining particle (TRP) in the presence of Thought force $\left(T_{F}\right)$ in vitro and Thought force $\left(\mathrm{T}_{\mathrm{F}}\right)$ in vivo
}

\author{
Dhananjay Pal

\section{Email address:} \\ dhananjay.pal123@gmail.com,paldhananjay46@yahoo.com
}

Pharmacy College, Bengal School of Technology, Sugandha-Delhi Road, Chuchura, Dist.-Hooghly, West Bengal, INDIA

\section{To cite this article:}

Dhananjay Pal. Explanation of Mental Processes Involving Consciousness through the Consciousness Model Incorporating Quantum Mechanical Activities of Though-Carrying Particle (TCP) and Thought Retaining Particle (TRP) in the Presence of Thought Force ( $\left.\mathrm{T}_{\mathrm{F}}\right)$ in vitro and Thought Force ( $\mathrm{T}_{\mathrm{F}}$ ) in vivo. American Journal of Physics and Applications. Vol. 1, No. 3, 2013, pp. 59-66. doi: 10.11648/j.ajpa.20130103.13

\begin{abstract}
A single field emerged at the origin of the universe, already containing within itself the blueprint of the physical universe. The primordial single field triggered the onset of the universe. Most physicists believe that a single super-force dominated the first instants of creation. Scientists have arrived at a simple but decisive conclusion that consciousness is very much a part of the universe, like other objects. Our consciousness model involving thought-carrying particle (TCP), thought retaining particle (TRP) and thought force $\left(\mathrm{T}_{\mathrm{F}}\right)$ signifies the existence of universal consciousness that exists along with the universe. This universal consciousness is a functional state of the universal mind. This universal mind (UM) is evolved at the Big Bang from void. The UM is constituted by these TCP and TRP in the inherent presence of thought force $\left(T_{F}\right)$. Thought force $\left(T_{F}\right)$ is an expression of universal consciousness. The Thought force $\left(T_{F}\right)$ being the primordial quantum field functions as the original super-force. $\mathrm{T}_{\mathrm{F}}$ being the original super-force functions as the origin of all the fundamental fields. TCP is the carrier of thought force $\left(\mathrm{T}_{\mathrm{F}}\right)$ that, in turn, appears to be the origin of all the fields. The quantized energy $\left(\varepsilon_{T}\right)$ of TCP is responsible to cause the universal consciousness as well as the cosmic microwave background radiation temperature. The individual consciousness owes its origin to the universal consciousness created by the same $\varepsilon_{T}$. The same $\mathcal{E}_{T}$ is the energy responsible for generating thought force $\left(\mathrm{T}_{\mathrm{F}}\right)$. $\mathrm{T}_{\mathrm{F}}$ being an expression of the universal consciousness is applicable to any inanimate object as well as to any biological system (having thinking ability). The $\mathrm{T}_{\mathrm{F}}$ exerts its functions both in vitro and in vivo. We showed the existence of thought force in microcosm [ $\left.\mathrm{T}_{\mathrm{F}}(\mathrm{micro})\right]$ and thought force in macrocosm $\left[\mathrm{T}_{\mathrm{F}}\right.$ (macro)]. This $\mathrm{T}_{\mathrm{F}}$ (micro) is theoretically found to be stronger than the strong nuclear force. $\mathrm{T}_{\mathrm{F}}$ (macro) is theoretically found to be weaker even than the gravitational force. Any matter as well as the individual mind is constituted by these TCP and TRP that are originated from the same Void. There is no theory to explain mental processes. Mental processes involving consciousness can be explained through these TCP and TRP in the presence of Thought force $\left(\mathrm{T}_{\mathrm{F}}\right)$ in vitro and Thought force $\left(\mathrm{T}_{\mathrm{F}}\right)$ in vivo.
\end{abstract}

Keywords: Universal Mind (UM), Thought Force $\left(\mathrm{T}_{\mathrm{F}}\right)$, Though-Carrying Particle (TCP), Thought Retaining Particle (TRP), Quantized Energy ( $\varepsilon_{T}$ ) of TCP, Universe Wide Web (UWW), Cosmic Microwave Background Radiation (CMBR)

\section{Introduction}

It is most relevant and important to indicate the names of various eminent physicists like Erwin Schrödinger, Eugene Wigner, Brian Josephson, John Wheeler, Roger Penrose, Henry P Stapp, Freeman J. Dyson, Paul Davies, David 
Bohm, Basil Hiley, Fritjof Capra, Fred Alan Wolf and Amit Goswami who have addressed the inclusion of consciousness in their work. Consciousness is to be taken into account.

1.1. Consciousness model of Pal et al [1-3] involving TCP, TRP and thought force $\left(\mathrm{T}_{\mathrm{F}}\right)$ signifies the existence of universal consciousness that exists along with the universe. Pal et al [3] showed that this universal consciousness is a functional state of the Universal Mind (UM). Pal et al [3] explained that the UM is evolved at the Big Bang from the eternal Void (see Scheme-I). This Void, in turn, is the source of infinite energy. And this UM is a finer matter. The individual mind being a constituent of the UM is also a finer matter. The constituents of the UM and individual mind are the same. The ultimate constituents of matter and mind are the same as both mind and matter are aspects of one fundamental reality, which is called UM. The brain is the mediating link or interface between the individual mind and body.

Pal et al [3] explained that the constituents of the UM are the ultimate constituents of matter itself as everything in this universe is a manifestation of this UM. Pal et al [3] expressed that the UM is constituted by these TCP and TRP in the inherent presence of thought force $\left(\mathrm{T}_{\mathrm{F}}\right)$. Pal et al $[1,3]$ further explained that the ultimate constituents of matter and mind are these TCP and TRP in the inherent presence of thought force $\left(\mathrm{T}_{\mathrm{F}}\right)$ in vitro and thought force $\left(\mathrm{T}_{\mathrm{F}}\right)$ in vivo [See Scheme-I].

Pal et al [1,3] further explained that the existence of universal consciousness is the primary cause for the evolution of life. Without the inherent existence of universal consciousness, the inanimate matter itself cannot generate life and consciousness. These TCP and TRP, the constituents of the UM and the ultimate constituents of matter and mind are conceived here to be originated from the Void at the Big Bang to evolve the space-time continuum and the UM along with the universal consciousness. Thought force $\left(\mathrm{T}_{\mathrm{F}}\right)$, an expression of this universal consciousness, is thus the primordial quantum field and it exerts its functions both in vitro and in vivo.

Physicists determined that underlying quantum fields give birth to elementary particles. Bhaumik [4] mentioned that Frank Wilczek pointed out, "In quantum field theory, the primary elements of reality are not individual particles, but underlying fields. Thus, for example, all electrons are but excitations of an underlying field, naturally called electric field". The same holds true for all the fundamental particles of which matter is made.

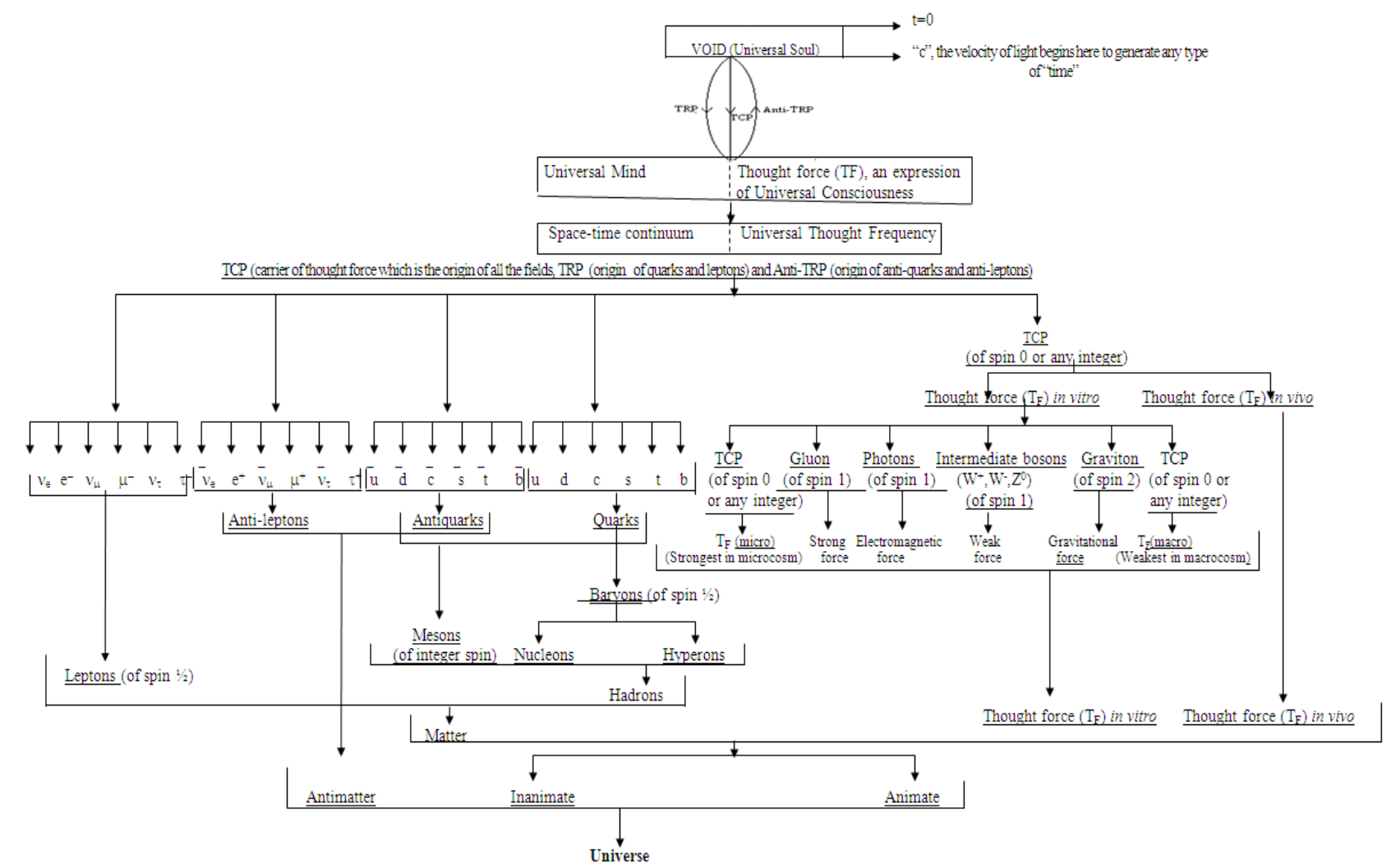

Scheme-I: Schematic presentation showing the evolution of the universe from the Void incorporating the postulated TCP (Thought-carrying particle), TRP (Thought-retaining particle) and Thought Force $\left(T_{F}\right)$. Laws of absolute conservation of mass, charge (and color) are to be maintained in order to develop a general theory for the unification of physics which would be freely applicable to the more general situations involving both the non-living system and living system having consciousness. Here TCP is the carrier of thought force $\left(T_{F}\right)$ that is the origin of all the fields. TRP is the origin of all the matter particles. It is to be noted that these TCP and TRP function like wavicle: wave-particle duality. Here thought force ( $\left.T_{F}\right)$ is an expression of the universal consciousness 
Thought force $\left(\mathrm{T}_{F}\right)$ [is a single super-force that dominated the first instants of creation and it is the primordial quantum field] [The thought force $\left(\mathrm{T}_{\mathrm{F}}\right.$ ) is carried by the TCP (thought-carrying particle) in the presence of its super-symmetrical partner TRP (thought retaining particle)]

Thought force $\left(\mathrm{T}_{\mathrm{F}}\right)$ in vitro [The non-living system of the world is governed by the thought force $\left(\mathrm{T}_{\mathrm{F}}\right)$ in vitro] $\downarrow$

$\mathrm{T}_{\mathrm{F}}$ (micro), SNF, EMF, WNF, GF and $\mathrm{T}_{\mathrm{F}}$ (macro)

where $\mathrm{T}_{\mathrm{F}}(\mathrm{micro})=$ Thought force in microcosm, $\mathrm{SNF}=$ Strong nuclear force,

$\mathrm{EMF}=$ Electromagnetic force, $\mathrm{WNF}=$ Weak nuclear force,

$\mathrm{GF}=$ Gravitational force and $\mathrm{T}_{\mathrm{F}}($ macro $)=$ Thought force in macrocosm.

It is expressed here that $\mathrm{T}_{\mathrm{F}}$ (micro) is a stronger force than the SNF and

$\mathrm{T}_{\mathrm{F}}($ macro) is a weaker force even than the GF. $\downarrow$

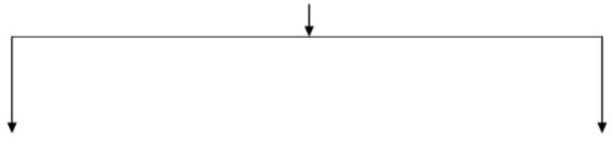

Thought force $\left(\mathrm{T}_{\mathrm{F}}\right)$ in vivo [The living system of the world is governed by the thought force $\left(\mathrm{T}_{\mathrm{F}}\right)$ in vivo]
Scheme-II: Thought force and its significant roles: Most physicists believe that a single super-force dominated the first instants of creation. This mysterious super-force is the postulated Thought force $\left(\mathrm{T}_{\mathrm{F}}\right)$. It is possible that the evolution of all the fundamental fields is originated from this super-force that is the Thought force $\left(\mathrm{T}_{\mathrm{F}}\right)$ in our view. This thought force $\left(\mathrm{T}_{\mathrm{F}}\right)$ is carried by the TCP (thought-carrying particle) in the presence of its super-symmetrical partner TRP (thought retaining particle). $\mathrm{TCP}$ is the carrier of thought force $\left(\mathrm{T}_{\mathrm{F}}\right)$ that, in turn, is the origin of all the fields. TCP is the origin of all the field particles. TRP is the origin of all the matter particles. TCP cannot exist without TRP and vice versa. Our consciousness model involving TCP, TRP and thought force ( $\mathrm{T}_{\mathrm{P}}$ ) signifies the existence of universal consciousness that exists along with the universe. We showed that the quantized energy $\left(\varepsilon_{T}\right)$ of the TCP is responsible to cause the universal consciousness as well as the cosmic microwave background radiation temperature. The individual consciousness owes its origin to the universal consciousness created by the same $\varepsilon_{T}$. The same $\varepsilon_{T}$ is the energy responsible for generating Thought force $\left(\mathrm{T}_{\mathrm{F}}\right)$. Thus, Thought force $\left(\mathrm{T}_{\mathrm{F}}\right)$ is an expression of the universal consciousness. Thought force $\left(\mathrm{T}_{\mathrm{F}}\right)$ being an expression of the universal consciousness is applicable to any inanimate object as well as to any biological system (having thinking ability). The Thought force $\left(\mathrm{T}_{\mathrm{F}}\right)$ exerts its functions both in vitro and in vivo. The non-living system of the world is governed by the thought force $\left(\mathrm{T}_{\mathrm{F}}\right)$ in vitro and this Thought force $\left(\mathrm{T}_{\mathrm{F}}\right)$ in vitro gives rise to $\mathrm{T}_{\mathrm{F}}($ micro), $\mathrm{SNF}$, EMF, WNF, GF and $\mathrm{T}_{\mathrm{F}}$ (macro) where $\mathrm{T}_{\mathrm{F}}($ micro $)=$ Thought force in microcosm, $\mathrm{SNF}=$ Strong nuclear force, $\mathrm{EMF}=$ Electromagnetic force, $\mathrm{WNF}=$ Weak nuclear force, $\mathrm{GF}=$ Gravitational force and $\mathrm{T}$ $($ macro $)=$ Thought force in macrocosm. It is to be noted here that $\mathrm{T}_{\mathrm{F}}($ micro) is a stronger force than the SNF and $\mathrm{T}_{\mathrm{F}}$ (macro) is a weaker force even than the GF. The living system of the world is governed by the thought force $\left(\mathrm{T}_{\mathrm{F}}\right)$ in vivo and this Thought force $\left(\mathrm{T}_{\mathrm{F}}\right)$ in vivo is a type of force that

The existence of matter depends on the existence of force and vice versa. TCP cannot exist without TRP and vice versa. Many physicists believe that unifying all the forces, including gravity, into a single theory would require a phenomenon called super-symmetry. With supersymmetry, every fermion would have a boson twin, and vice-versa. The thought force $\left(\mathrm{T}_{\mathrm{F}}\right)$ is carried by the TCP in the presence of its super-symmetrical partner TRP. TCP that behaves like boson should accompany its supersymmetrical partner TRP that functions like fermion in the generalized simpler way. It is to be noted that these TCP and TRP function like wavicle: wave-particle duality.

1.2. Pal et al [1-3] showed that the quantized energy $\left(\varepsilon_{T}\right)$ of TCP is responsible to cause the universal consciousness as well as the cosmic microwave background radiation temperature. Here thought force $\left(\mathrm{T}_{\mathrm{F}}\right)$ is an expression of the universal consciousness which exists along with the universe. And the quantized energy $\left(\mathcal{E}_{T}\right)$ of TCP represents universal consciousness. represents the biological 'thought' which is the action of mind. This 'thought' being a type of force controls the 'thought processes' involving the firing of neurons through the quantum mechanical activities of these postulated TCP and TRP in the presence of consciousness. This consciousness, in turn, is the quantized energy $\left(\varepsilon_{\tau}\right)$ of the TCP. Thought force $\left(\mathrm{T}_{\mathrm{F}}\right)$ being the primordial quantum field functions as the original single primary unified field that is not only the origin of all the four fundamental fields along with both the $\mathrm{T}_{\mathrm{F}}$ (micro) and $\mathrm{T}_{\mathrm{F}}$ (macro) but also the origin of Thought force $\left(\mathrm{T}_{\mathrm{F}}\right)$ in vivo.

Note: What was previously called a force is now usually called a field or interaction. The existence of matter depends on the existence of force and vice versa. Matter particles are usually designated as "Fermions", because they follow Fermi-Dirac Statistics. Matter particles obey Pauli's exclusion principle; they are of spin $1 / 2$. Force particles are usually designated as "Bosons", because they follow Bose-Einstein Statistics. Force particles do not obey Pauli's exclusion principle; they are of spin o, or any integer like 1, 2, 3 etc. TCP cannot exist without TRP and vice versa. Many physicists believe that unifying all the forces, including gravity, into a single theory would require a phenomenon called super-symmetry. With super-symmetry, every fermion would have a boson twin, and vice-versa. TCP that behaves like boson should accompany its super-symmetrical partner TRP that functions like fermion in the generalized simpler way.

\section{Thought Force}

Pal et al [1, 3] and Pal [5] explained the existence of thought force $\left(\mathrm{T}_{\mathrm{F}}\right)$. Thought force $\left(\mathrm{T}_{\mathrm{F}}\right)$, an expression of the universal consciousness, is the primordial quantum field that, in turn, functions as the primary unified field. This $T_{F}$ being an expression of the universal consciousness is applicable to any inanimate object as well as to any biological system (having thinking ability). Thus the $T_{F}$ being an expression of the universal consciousness exerts its functions both in vitro and in vivo (see Scheme-I and Scheme-II).

Physicists determined that underlying quantum fields give birth to elementary particles. Pal [5] expressed that the thought force $\left(\mathrm{T}_{\mathrm{F}}\right)$ is the primordial quantum field. Thought force $\left(\mathrm{T}_{\mathrm{F}}\right)$ being the primordial quantum field functions as the primary unified field. Thought force $\left(T_{F}\right)$ being the primordial quantum field gives birth to TRP that appears to be the origin of all the matter particles. TCP is the carrier of thought force $\left(\mathrm{T}_{\mathrm{F}}\right)$ that, in turn, appears to be the origin of 
all the fields. TCP thus appears to be the origin of all the field particles.

In a purpose to involve both the non-living and living systems of the world, Pal [5] has shown the existences of these TCP, TRP and thought force $\left(\mathrm{T}_{\mathrm{F}}\right)$ in vitro and thought force $\left(\mathrm{T}_{\mathrm{F}}\right)$ in vivo. Anyone can call this TCP by any other name, but as the highly developed living system will have to be evolved in the universe in the long run and as the thought of highly developed living system appears to be a kind of force to be called the thought force $\left(\mathrm{T}_{\mathrm{F}}\right)$ in vivo, we considered it is wise to call it as TCP. Further, as the universe exists along with the universal consciousness that, in turn, is created by the quantized energy $\left(\varepsilon_{T}\right)$ of TCP, we had to use the term TCP.

Pal (5) expressed that the non-living system of the world is governed by the thought force $\left(\mathrm{T}_{\mathrm{F}}\right)$ in vitro and this Thought force $\left(\mathrm{T}_{\mathrm{F}}\right)$ in vitro gives rise to $\mathrm{T}_{\mathrm{F}}$ (micro), $\mathrm{SNF}$, EMF, WNF, GF and $\mathrm{T}_{\mathrm{F}}$ (macro) where $\mathrm{T}_{\mathrm{F}}$ (micro) = Thought force in microcosm, SNF $=$ Strong nuclear force, $\mathrm{EMF}=$ Electromagnetic force, $\mathrm{WNF}=$ Weak nuclear force, $\mathrm{GF}=$ Gravitational force and $\mathrm{T}_{\mathrm{F}}($ macro $)=$ Thought force in macrocosm. It is to be noted here that $\mathrm{T}_{\mathrm{F}}$ (micro) is a stronger force than the SNF and $\mathrm{T}_{\mathrm{F}}$ (macro) is a weaker force even than the GF.

$\mathrm{Pal}$ (5) also expressed that the living system of the world is governed by the thought force $\left(\mathrm{T}_{\mathrm{F}}\right)$ in vivo and this Thought force $\left(\mathrm{T}_{\mathrm{F}}\right)$ in vivo is a type of force that represents the biological 'thought' which is the action of mind. This 'thought' being a type of force controls the 'thought processes' involving the firing of neurons through the quantum mechanical activities of these TCP and TRP in the presence of consciousness. Consciousness in living organisms is a process which involves the quantum mechanical activities of these TCP and TRP, the ultimate constituents of any matter as well as any mind in the inherent presence of thought force $\left(\mathrm{T}_{\mathrm{F}}\right)$ in vitro and the thought force $\left(\mathrm{T}_{\mathrm{F}}\right)$ in vivo as indicated by Pal [5]. These TCP and TRP govern the activities of neurons (not the other way round). Neurons are simply the equipments used to generate consciousness and awareness. This consciousness, in turn, is the quantized energy $\left(\varepsilon_{T}\right)$ of TCP. The thought force $\left(\mathrm{T}_{\mathrm{F}}\right)$ in vivo is demonstrated in numerous experiments in which thought has an effect on a physical process (often known as mind over matter). This biological 'thought' is a type of force that can cause movement. Controlling movement through thought alone is observed in several experiments conducted by many scientists as indicated by Pal (5). These experiments thus signify the existence of thought force $\left(\mathrm{T}_{\mathrm{F}}\right)$ in vivo.

Pal [5] explained the existence of $\mathrm{T}_{\mathrm{F}}$ (micro) $(=$ Thought force in microcosm). This $\mathrm{T}_{\mathrm{F}}$ (micro) is the strongest interaction (a new class of 'extra strong' interaction). It is stronger than SNF (Strong Nuclear Force).

Pal [5] has also shown the existence of $\mathrm{T}_{\mathrm{F}}$ (macro) (= Thought force in macrocosm). It is the "weakest force" which is much weaker even than the gravity.

\subsection{Pal Et Al [3] Expressed That the CMBR Temperature Is Due To $\varepsilon_{T}$, the Quantized Energy of TCP}

Where $\varepsilon_{T}=4.384 \times 10^{-16} \mathrm{erg} \equiv 2.73^{\circ} \mathrm{K}$ that is very close to $2.725^{\circ} \mathrm{K}$ (CMBR temperature). As per Pal et al [3], it is interesting to note that all of the three different equations ultimately give rise to the same result that is equivalent to the CMBR temperature. A sort of relationship is thus observed between the $\varepsilon_{T}$ and the CMBR temperature. This coincidence is thus signifying a probable role of TCP on the maintenance of CMBR temperature. Further, this coincidence also signifies the existence of these TCP in the presence of TRP. TCP cannot exist without TRP and vice versa. The presence of TCP, TRP and Thought force $\left(T_{F}\right)$ in the universe is thus indicated and expressed mathematically. At present we are unable to explain when and how these TCP and TRP decoupled from the primordial cosmic soup.

\subsection{Copenhagen Interpretation}

Samanta-Laughton [6] expressed, "At a quantum level particles can exist in many states at a time. What brings them out of this superposition is a matter of debate, but according to the Copenhagen interpretation, it is the act of observing a particle that determines what it is. Bohr went further and said that there is no objective reality 'out there'. Things only exist when we observe them. This implies that the whole universe exists only in our consciousness. Although controversial, the Copenhagen interpretation has stood the test of time with its bizarre philosophical implications".

The reigning tenet of quantum mechanics is the uncertainty principle. A consequence of the uncertainty principle is that the presence of an observer or experimenter determines the outcome of the observation or experiment. Simply stated, this means there is no objective reality; you 'create' what you see through the quantum mechanical activities of these TCP and TRP in the presence of consciousness. The quantized energy $\left(\varepsilon_{T}\right)$ of TCP represents universal consciousness. The individual consciousness owes its origin to the universal consciousness created by the same $\varepsilon_{T}$. And these TCP and TRP are the ultimate constituents of any matter as well as any mind in the inherent presence of thought force $\left(\mathrm{T}_{\mathrm{F}}\right)$ in vitro and the thought force $\left(\mathrm{T}_{\mathrm{F}}\right)$ in vivo as it is indicated by Pal et al $[1,3]$.

How could an object's existence depend upon the act of observation? This is due to the fact that an object's existence as well as the act of observation through the prevailing consciousness is totally dependent on the existence of the quantum mechanical activities of these TCP and TRP in the presence of consciousness. The quantized energy $\left(\varepsilon_{T}\right)$ of TCP represents universal consciousness. The individual consciousness owes its origin to the universal consciousness created by the same $\varepsilon_{T}$. And these TCP and TRP are the ultimate constituents 
of any matter as well as any mind in the inherent presence of thought force $\left(\mathrm{T}_{\mathrm{F}}\right)$ in vitro and the thought force $\left(\mathrm{T}_{\mathrm{F}}\right)$ in vivo as indicated by $\mathrm{Pal}$ et al $[1,3]$.

\section{What Is Life}

Life is a state of flux that is being maintained by a typical form of energy which is nothing but the consciousness itself. Pal et al [3] and Pal [7] showed that the quantized energy $\left(\varepsilon_{T}\right)$ of TCP is responsible to cause the universal consciousness as well as the cosmic microwave background radiation temperature. The individual consciousness owes its origin to the universal consciousness created by the same $\varepsilon_{T}$. Pal et al $[1,3]$ and Pal [7] explained that life may be defined as a state of functional manifestation of consciousness that, in turn, is the quantized energy ( $\varepsilon_{T}$ ) of TCP. This $\mathcal{E}_{T}$ represents universal consciousness.

$$
\text { Thus, Life }=\mathrm{f}(\text { Consciousness })=\mathrm{f}\left(\boldsymbol{\varepsilon}_{T}\right)
$$

$$
\begin{aligned}
& \text { where } \varepsilon_{T}=\text { quantized energy of the TCP } \\
& =4.384 \times 10^{-16} \mathrm{erg} . \\
& \varepsilon_{T}=h v_{T}=h c / \lambda_{T}=4.384 \times 10^{-16} \mathrm{erg}
\end{aligned}
$$

where $\varepsilon_{T}=$ quantized energy of the TCP $=4.384 \times 10^{-16} \mathrm{erg}$,

$$
\begin{gathered}
v_{T}=\text { frequency of the } \mathrm{TCP}= \\
\varepsilon_{T} / h=66.12 \times 10^{9} \mathrm{~Hz} .=66.12 \mathrm{GHz}, \\
\mathrm{h}=\text { Planck's quantum constant }=6.63 \times 10^{-27} \mathrm{erg} . \mathrm{sec}, \\
\mathrm{c}=\text { free-space velocity of light }=3 \times 10^{10} \mathrm{~cm} / \mathrm{sec}, \\
\lambda_{T}=\text { wave-length of the } \mathrm{TCP}=0.4537 \mathrm{~cm} .
\end{gathered}
$$

\subsection{What Is Consciousness}

Psychologists, neuroscientists, philosophers, and other professionals continue to engage in an ongoing debate as to what consciousness means. In reality, we may never know. Is it a product of the biological and classical physical interactions of the human brain; or is it something more fundamental, perhaps electromagnetic, or the result of quantum physics principles that we don't yet fully understand? Could it be something even more profound than that -- something beyond the scope of science and physics, any kind of physics, for us to understand?

According to the ancient Vedanta, consciousness is not an emergent property of matter that comes into existence only through the functioning of the human nervous system. Instead, consciousness is a characteristic of reality, pervading all manifestations. This unbounded field of nature's universal consciousness is not limited to an individual consciousness. From this viewpoint, the role of the human nervous system is to provide an appropriate material structure to individualize consciousness. It appears that inanimate matter itself cannot generate consciousness without the inherent existence of universal consciousness. Consciousness in living organisms is a process which involves the quantum mechanical activities of these TCP and TRP, the ultimate constituents of any matter as well as any mind in the inherent presence of thought force $\left(\mathrm{T}_{\mathrm{F}}\right)$ in vitro and the thought force $\left(\mathrm{T}_{\mathrm{F}}\right)$ in vivo as indicated by Pal et al $[1,3]$. And these TCP and TRP govern the activities of neurons (not the other way round). Neurons are simply the equipments used to generate consciousness and awareness.

Pal et al [2] explained, "Consciousness is the realization of existence, and there are as many states of consciousness as there are states of existence. Every living being has a consciousness of its own depending on complexity of the brain and the activity of the viable numbers of TCP in the presence of TRP; and the state of its consciousness changes every moment of time. Consciousness is the perception of the relation it bears to things and as this relation changes, consciousness changes its character. Consciousness itself does not change; it only moves up and down on the 'scale of the realization' of existence through the 'sub-conscious', 'conscious' and 'super-conscious' states". There is another term called unconscious state. The most usual unconscious state is sleep. A deeper form of unconsciousness is called a coma.

It appears that

$$
\text { Consciousness }=\mathrm{f}(\text { mind })
$$

Consciousness is the functional state of mind. Presence of consciousness signifies the presence of mind and vice versa.

\section{It is apparent that}

$$
\text { Animate } \neq \text { Inanimate }
$$

Three critical factors which distinguish life from nonliving are consciousness, metabolism and reproduction. (4):

In a gross presentation, we can express from the equation

$$
\text { Animate }- \text { Consciousness }=\text { Inanimate }
$$

Scientists would have to define and characterize consciousness properly. We should have the proper knowledge about the exact characteristics of consciousness in order to address many present day scientific enigmas.

\section{What Is the Exact Definition of Mind}

We observe a great controversy concerning the exact definition of mind. There are two apparently opposite views: one is the substantial view and the other is the functional view.

In the substantial view, the mind is a type of substance. Mind is a finer matter having an autonomous existence. Mind is a single entity, perhaps having its base in the brain but distinct from it. In its most extreme form as in the Indian Upanishads and Vedanta, the mind is not only a finer matter but also it is an entity wholly separate from the body, in fact a manifestation of the soul, which will survive the 
body's death in the form of the spiritual body or mental body [called Linga Sharira or Sukshma Sharira in Sanskrit] as expressed by Vivekananda [8] who indicated that this mental body bears all the mental impressions. This mental body is also called 'spirit'.

In the functional view, the mind is closely related to the functions of the brain and can have no autonomous existence beyond the brain, nor can they survive its death. In this view, mind is a 'state' created by the activities of the brain with other parts of the nervous system as it is indicated by cognitive neuro-scientists and Artificial Intelligence (AI) scientists. According to them 'minds are simply what brains do'. In this functional view, mind is a subjective manifestation of consciousness: the human brain's ability to be aware of its own existence. The concept of the mind is therefore a means by which the conscious brain understands its own operations.

Modern Scientists are not yet able to understand how the brain works to make the mind. They know that brain has got neurons that communicate across synapses by releasing a neurotransmitter, and that generates electrical impulses, and the receiving neuron then talks to its neighbor neurons the same way. If the mind depends on the brain, then all aspects of the mind are going to depend on these simple electrical, chemical processes. According to this concept, the existence of the UM requires the existence of the universal brain to form the UM. The concept of universal brain is not logically acceptable. Thus the concept that the mind depends on the brain becomes questionable if the existence of the UM is valid.

The basic mystery of the mind is how does it emerge from pure matter? How do those units that are made of tiny particles, give rise to the unique and essentially private, experience called consciousness? Do the particles that constitute our brain determine what we think and do? Do these tiny particles ultimately govern the thinking ability of the bioelectrical system? Or, are we free to have our own will? Is consciousness just froth sitting on top of the brain's electronics? How consciousness is being operated? Why should a bunch of atoms have thinking ability? Gross answers to all these inquiries are possible if we accept these TCP and TRP as the ultimate constituents of mind and matter as indicated by $\mathrm{Pal}$ et al [3].

We are what our minds make us. The mind is a very powerful controller of the body. The mind controls everything as indicated by Pal et al [1,3] and Pal [7]. Mind is conditioned from the time we are young. It gives our abilities, our perceptions, our character and the way we think. From science to religion, from politics to economics, everything is controlled by the human mind. We perceive, we believe and we react. Things that matter are what we think they are. The quest for truth is bafflingly elusive, after all what is the 'truth'? We have come to the realization that if I believe it is true, it indeed is true for me, regardless of how incredible you may think it is. Experiments do not matter, arguments do not matter, reality does not matter, in fact, matter does not matter---it is all in the mind. As a joker succinctly put it, "It is a case of mind over matter-I do not mind and you do not matter".

The modern cognitive neuroscientists generally accept the fact that the "mind" is not an isolated entity and the mind is a state created by the activities of brain with other parts of the nervous system (CNS, PNS along with ANS). Although the mind is generally accepted to be an abstract having no spatial location or public observability, yet it is a type of fine matter according to the ancient Indian Upanishads and Vedanta. The Vedanta indicates that the universe exists along with the universal consciousness. This universal consciousness is a functional state of the Universal Mind. Pal et al [1,3] explained that any matter as well as any individual mind is constituted by these TCP and TRP in the inherent presence of Thought force $\left(\mathrm{T}_{\mathrm{F}}\right)$ in vitro and Thought force $\left(\mathrm{T}_{\mathrm{F}}\right)$ in vivo.

4.1. It appears that scientists would have to decide in a purpose to conclude clearly whether mind is a 'state' (created by the activities of the brain with other parts of the nervous system as it is indicated by the functional view of mind) or 'a finer matter' (as it is indicated by the Indian Upanishads and Vedanta).

\section{Characteristics of Elusive Soul ( $\cong$ VOID), Mind and Consciousness}

Consciousness model of Pal et al [1-3] involving TCP, TRP and thought force $\left(\mathrm{T}_{\mathrm{F}}\right)$ signifies the existence of universal consciousness that exists along with the universe. Pal et al [3] showed that this universal consciousness is a functional state of the Universal Mind (UM). Pal et al [3] explained that the UM is evolved at the Big Bang from the eternal Void (see Scheme-I). The UM is constituted by these TCP and TRP in the inherent presence of thought force $\left(T_{F}\right)$. This thought force $\left(T_{F}\right)$ is an expression of universal consciousness.

These TCP and TRP, the constituents of the UM and the ultimate constituents of matter and mind are conceived here to be originated from the eternal Void at the Big Bang to evolve the space-time continuum and the UM along with the universal consciousness.

Pal et al [3] explained that the eternal Void has been covered by the mind to function as the Soul of the individual being. In the universe, behind the UM, there is a Soul ( $\cong$ VOID). In the individual, behind the individual mind (which is a constituent of the UM), there is also a Soul ( $\cong$ VOID).

Pal et al [3] indicated that Soul ( $\cong$ Void) being the master ruler of the body exerts its functions through the finer instrument called mind. The mind (with the help of TCP and TRP) exerts its functions through the brain and spinal cord (CNS) along with the other parts of the nervous system (PNS along with ANS) in the biological systems in order to grasp this physical universe, of course, in the inherent presence of consciousness. This consciousness itself is acting as an inter-linking agent between the animate and inanimate through the quantum mechanical activities of these TCP and TRP. Consciousness is defined here as the 
'self-organized' capability of any living being to activate TCP and TRP, the ultimate constituents of mind and matter. This consciousness, in turn, is the quantized energy $\left(\varepsilon_{T}\right)$ of TCP.

Any matter as well as the individual mind is constituted by these TCP and TRP that, in turn, are originated from the same eternal Void. Thus the individual mind is operated by these TCP and TRP that, in turn, are ultimately governed by the same eternal Void. The individual mind being a constituent of the UM has covered the eternal Void to serve the role of individual Soul. This eternal Void is thus the common source and the source is still with us indicated by Bhaumik [4]. This Void serves the role of Soul being covered by the mind.

\section{Mental Processes Involving Consciousness Are Possible to Be Explained Through the Quantum Mechanical Activities of TCP and TRP in the Presence of Thought Force $\left(\mathrm{T}_{\mathrm{F}}\right)$ in Vitro and Thought Force $\left(\mathrm{T}_{\mathrm{F}}\right)$ in vivo}

It can be shown that

$$
\begin{gathered}
v_{T}=\text { frequency of the TCP }= \\
\varepsilon_{T} / h=66.12 \times 10^{9} \mathrm{~Hz} \cdot=66.12 \mathrm{GHz}
\end{gathered}
$$

It is also to be noted that when $\varepsilon_{T}=4.95 \times 10^{-16} \mathrm{erg}$ and $\mathrm{h}=6.63 \times 10^{-27} \mathrm{erg} . \mathrm{sec}$, then

$$
\begin{gathered}
v_{T}=\text { frequency of the TCP }= \\
\varepsilon_{T} / h=74.66 \times 10^{9} \mathrm{~Hz} \cdot=74.66 \mathrm{GHz} \cong 75 \mathrm{GHz} \\
\tau_{T}=\text { time period of the TCP }=h / \varepsilon_{T}=1.33 \times 10^{-11} \mathrm{sec} .
\end{gathered}
$$

Georgiev [9] explained through experimental observation that our mind operates at $100 \mathrm{GHz}$ (dynamical timescale of 10 picoseconds). It is found that the calculated frequency of TCP is $75 \mathrm{GHz}$ that is close to $100 \mathrm{GHz}$. and the calculated time period of the TCP $=1.33 \times 10^{-11} \mathrm{sec}$ that is equivalent to 10 picoseconds $=10^{-11} \mathrm{sec}$.

It appears that there is a significant relationship between the operational mind and the quantum mechanical activities of these TCP and TRP. In this way, the mind is a state created by these TCP and TRP. Or the mind is constituted and operated by these TCP and TRP. These TCP and TRP can thus form a possible bridge between the mind and matter in the presence of thought force $\left(\mathrm{T}_{\mathrm{F}}\right)$ in vitro and thought force $\left(\mathrm{T}_{\mathrm{F}}\right)$ in vivo.

\subsection{Neuronal Infrastructure Is Required for the Manifestation of Consciousness}

Hameroff and Penrose [10, 11] mentioned, current neurophysiological explanations of consciousness suggest that it is a manifestation of emergent firing patterns of neuronal groups involved in either a) specific networks (e.g Hebb, 1949; 1980; Freeman, 1975; 1978), coherent 40-80 $\mathrm{Hz}$ firing (e.g. von der Marlsburg and Schneider, 1986; Gray and Singer, 1989; Crick and Koch, 1990) and/or attentional scanning circuits (e.g. Crick, 1984; Edelman, 1989; Baars, 1988; 1993).

There are about $10^{11}$ neurons in the brain. Out of $10^{11}$ neurons, OrchOR (Orchestrated Objective Reduction) indicated by Hameroff and Penrose $[10,11]$ predicts involvement of roughly $10^{2}$ to $10^{3}$ neurons (interconnected by gap junctions) for rudimentary conscious events. For more intense conscious events, for example consistent with 25 msec "cognitive quanta" defined by coherent $40 \mathrm{~Hz}$ activity (e.g. Crick and Koch, 1990; c.f. Llinas, e.g. Joliot et al., 1994), superposition and self-collapse of $2 \times 10^{10}$ tubulins (and $10^{3}$ to $10^{4}$ neurons) would be required. It appears that gross $10^{2}$ neurons can give rise to $40-80 \mathrm{~Hz}$ firing (Crick and Koch, 1990).

$$
\begin{aligned}
& 10^{2} \text { neurons } \equiv(40-80) \text { Hzfiring } \\
& 10^{11} \text { neurons } \equiv \frac{(40-80) H z x 10^{11}}{10^{2}}=(40-80) \times 10^{9} \text { Hzfiring }
\end{aligned}
$$

Thus, for the thorough manifestation of consciousness involving $10^{11}$ neurons, we arrive at

$$
(40-80) x 10^{9} H z=(40-80) G H z \cong \nu_{T} \equiv
$$

Frequency of the TCP

$$
=\varepsilon_{T} / h=74.66 \times 10^{9} \mathrm{~Hz}=74.66 \mathrm{GHz} \cong 75 \mathrm{GHz} \text { as it is }
$$
expressed in the Equation (7).

It is found that the quantized energy $\left(\mathcal{E}_{T}\right)$ of TCP apparently plays significant roles in the generation and maintenance of universal consciousness. This specified $\mathcal{E}_{T}$ (= consciousness) is found to exist along with the universe. The individual consciousness owes its origin to the universal consciousness created by the same $\varepsilon_{T}$. Consciousness in living organisms is a process which involves the quantum mechanical activities of these TCP and TRP. These TCP and TRP govern the activities of neurons (not the other way round). These processes could also explain self-organization. 


\section{Discussion and Conclusion}

\subsection{Discussion}

Pal et al $[1,3]$ expressed that the cosmic microwave background radiation (CMBR) temperature exists due to the existence of $\varepsilon_{T}$ of TCP radiated from the radiant mass of universe. The existence of the CMBR temperature confirms the existence of TCP in the inherent presence of TRP. The existence of TCP indicates the existence of thought force $\left(\mathrm{T}_{\mathrm{F}}\right)$. Further, this $\mathrm{T}_{\mathrm{F}}$ exerts its functions both in vitro and in vivo. Pal [5] explained the testability for the existence of TCP and TRP along with the Thought force $\left(\mathrm{T}_{\mathrm{F}}\right)$. Pal [5] mentioned several experimental results to signify the existence of quantum mechanical activities of these TCP and TRP, the ultimate constituents of matter and mind in the inherent presence of thought force $\left(\mathrm{T}_{\mathrm{F}}\right)$ in vitro and the thought force $\left(\mathrm{T}_{\mathrm{F}}\right)$ in vivo.

Pal et al $[1,3]$ expressed that the mind-brain and brainbody links which are addressed by psychology, cognitive science, neuroscience and neurophysiology are ultimately governed by the quantum mechanical activities of these TCP and TRP. Consciousness that signifies the realization of existence is a functional state of mind.

The consciousness is created and maintained by the quantized energy $\left(\boldsymbol{\varepsilon}_{T}\right)$ of TCP in the inherent presence of TRP. Thus any matter (as well as mind) being ultimately composed of these TCP and TRP should have some sort of 'mind' as Dyson indicated. The more is the development of the organized brain, the more is the instrumental facility for the manifestation of consciousness as indicated by Pal et al. [2].

Pal et al $[1,3]$ explained that the consciousness itself is functioning as an inter-linking agent between the animate and inanimate through the quantum mechanical activities of these TCP and TRP that, in turn, could also explain selforganization. Consciousness may thus be defined as the 'self-organized' capability of any living being to activate TCP and TRP, the ultimate constituents of matter and mind, and to exert its functions.

\subsection{Conclusion}

There is no theory to explain mental processes. It is found through the experimental observations of Georgiev [9] that the mind is constituted and operated by these TCP and TRP in the presence of consciousness that, in turn, is the quantized energy ( $\left.\varepsilon_{T}\right)$ of TCP. These TCP and TRP can form a possible bridge between mind and matter in the presence of thought force $\left(\mathrm{T}_{\mathrm{F}}\right)$ in vitro and thought force $\left(\mathrm{T}_{\mathrm{F}}\right)$ in vivo. Pal et al [3] showed that these TCP and TRP are the ultimate constituents of any matter as well as any mind.
The mental processes involving consciousness can be explained through the quantum mechanical activities of these TCP and TRP in the presence of thought force $\left(\mathrm{T}_{\mathrm{F}}\right)$ in vitro and thought force $\left(\mathrm{T}_{\mathrm{F}}\right)$ in vivo. The role of TCP, TRP and thought force $\left(\mathrm{T}_{\mathrm{F}}\right)$ in vitro and thought force $\left(\mathrm{T}_{\mathrm{F}}\right)$ in vivo can explain the mental processes as well as the other psi phenomena.

\section{References}

[1] D. Pal and A.U. De, Physics of consciousness and its model may provide guidelines to solve many scientific problems. Neuroquantology 1: 17-28(2004)

[2] D. Pal and A.U. De, Consciousness model: Significance of thought-carrying particles and thought-retaining particles in quantum measurement as well as cognitive problem. Neuroquantology 2: 115-116 (2005)

[3] D. Pal and A.U. De, The cosmic microwave background radiation temperature signifying the existence of the thought-carrying particle, thought retaining particle and thought force. NeuroQuantology 10: Issue3; 428-442 (September 2012)

[4] M. Bhaumik, Code Name GOD. (Penguin Books India Pvt. Ltd., 11 Community Centre, Panchsheel Park, New Delhi 110017 , India) pp. 132-133; 161-162; 167; 171; 177; 185$186 ; 89-190 ; 198$ (2006)

[5] D. Pal, Existence of thought force and its characteristics. Communicated to American Journal of Modern Physics (AJMP) (2013)

[6] M. Samanta-Laughton, A Beginner's Guide to Consciousness. The Naked Scientists: Science Radio \& Science Podcasts 2005.

[7] D. Pal, Existence of universal consciousness and its characteristics. Accepted for publication in 2014 International Conference on Advanced Education and Management (ICAEM2014) Beijing, China (2013)

[8] S. Vivekananda, The Cosmos (the Microcosm). The complete works of Swami Vivekananda. (Advaita Ashrama, India) 2: pp-212 (1989)

[9] D. D. Georgiev, Consciousness operates beyond the timescale for discerning time intervals: implications for Qmind theories and analysis of quantum decoherence in brain. NeuroQuantology 2: 136 and 140-141 (2004)

[10] S. R. Hameroff and R. Penrose, Quantum coherence in microtubules: A neural basis for emergent consciousness. Journal of Consciousness Studies; 1: 91-118 (1994)

[11] S. R. Hameroff and R. Penrose, Conscious events as orchestrated space-time selections. Journal of Consciousness Studies 3: 36-53(1996) 